$\bullet \bullet \bullet$

\title{
The Diachronic Evolution of
}

the Complementation Profile of REMEMBER from Late Modern to Present-day

\section{British English}

LAURA GARCÍA-CASTRO 
145 NEUPHILOLOGISCHE MITTEILUNGEN - I CXXI 2020

The Diachronic Evolution of the Complementation Profile of REMEMBER

from Late Modern to Present-day British English

Abstract The emergence of gerund-participial complement clauses (CCs) is considered to be one of the major developments of the Great Complement Shift (Rohdenburg 1996: 2006) and has contributed to the alleged long-term trend for the growth of non-finite CCs in the English language (Denison 1999: 256). The verb REMEMBER saw its complementation profile altered by the introduction of gerundparticipial CCs, which entered into free competition with finite declarative CCs when the meaning of the verb is 'recall'. This envelope of variation is studied here in terms of frequency distribution and the language-internal factors that influence the choice in Present-day British English (BrE). Results are compared to Cuyckens et al. (2014) findings for the Late Modern English period. The data show that the distribution of finite and non-finite CCs stabilised in the last century, in that the trend in English towards growth in the proportion of nonfinite CCs is not observed in this study. As for factors conditioning CC variation, non-structural factors (e.g. CC MEANING) are key variables disfavouring non-finite CCs in Present-day BrE, while structural factors (e.g. COMPLEXITY CC NO. CONSTITUENTS) appear not to influence the choice today, unlike in Late Modern English, where both structural and non-structural factors conditioned the variation observed (Cuyckens et al. 2014).

\section{Introduction}

The current configuration of the complementation system of the English language is the result of an extensive reorganization that has been in progress since the Old English period (De Smet 2013: 44). Some of the most relevant changes were set into motion in Early Modern English, and took place in Modern times through a series of developments. These, in time, became radical changes in the inventory, frequency and distribution of the several complementation options available in the language (Fanego 2007: 162, 2016: 84-5; Rohdenburg 2014: 155; Seoane 2017: 77). Such changes have been termed the Great Complement Shift (by analogy to the Great Vowel Shift; Davies 2012: 57; cf. Rohdenburg 2003: 205, 2006: 143; Vosberg 2003: 197, 2009: 213; Rudanko 2012: 222). As with the Great Vowel Shift, the Great 
146 NEUPHILOLOGISCHE MITTEILUNGEN - I CXXI 2020

The Diachronic Evolution of the Complementation Profile of REMEMBER

from Late Modern to Present-day British English

Complement Shift took place gradually, starting with a set of matrix verbs, then extending to others (Davies 2012: 57).

One of the main changes in the complementation system of English was the emergence of the gerund-participial as a new non-finite complement clause (CC) in the Early Modern English period (Vosberg 2003: 197, 2009: 212; Fanego 2004b: 8; Rohdenburg 2006: 143; De Smet 2013: 131). This entailed English adding a third complementation option to the complementation profile of several verb classes. Thus, along with finite CCs, as in (1), and toinfinitival CCs, as in (2), which have both been available in English since the Old English period, gerund-participial CCs, as in (3), have been on the rise since their emergence in the late Middle English period. This has resulted in a rearrangement of the entire system of verb complementation (Vosberg 2003: 197-198).

1. I do remember that I haue red of a certain noble gentleman, (William Painter, The Palace of Pleasure, Tome 2, 1567; cf. Vosberg 2003: 197)

2. Take these royall rewardes of the Kyng, [...]: and remember to tell thy father, that (William Painter, The Palace of Pleasure, Tome 1, 1566; cf. Vosberg 2003: 197)

3. (...) but I remember turning down by that Shop into a blind Lane, (Richard Head/Francis Kirkman, The English Rogue, Part 4, 1671; cf. Vosberg 2003: 198)

As shown in Vosberg's (2003: 197-198) examples above, gerund-participial CCs entered the complementation profile of the verb REMEMBER, and later spread to other retrospective verbs such as REGRET and DENY (Fanego 2007: 175). These CCs established a relationship of competition with finite declarative CCs when the meaning of REMEMBER is 'recall'. Variation between finite declarative CCs, as in (4), and non-finite gerund-participial CCs, as in (5), continues to be non-categorical or probabilistic today; that is, it appears that the two alternatives are freely interchangeable (cf. Mair 2006; Cuyckens et al. 2014). 
147 NEUPHILOLOGISCHE MITTEILUNGEN - I CXXI 2020

Laura García-Castro • The Diachronic Evolution of the Complementation Profile of REMEMBER

from Late Modern to Present-day British English

4. I remember the impact of the bomb made all my clothes blow up -- (GloWbE GB)

5. When I was little I can remember my Nan making what she called potted rabbit, (...) (GloWbE GB)

This paper offers a corpus-based analysis of the CC variation illustrated above with the complement-taking predicate REMEMBER in Present-day British English (BrE). The aim of this analysis is twofold. First, to explore the frequency distribution of finite and non-finite CCs after REMEMBER meaning 'recall' in $\mathrm{BrE}$, and through this to identify the language-internal factors that determine this variation. This will make it possible to test the alleged probabilistic nature of complement choice in this envelope of variation. Second, to compare these results with the findings in Cuyckens et al. (2014) for the Late Modern English period. Such a diachronic comparison will serve to ascertain (i) whether the growth of non-finite CCs at the expense of finite CCs has continued, since this tendency has been described as a long-term trend in the English language (Denison 1999: 256; Rohdenburg 2003: 206, 2014: 156, 179; Vosberg 2003: 198; Fanego 2004a: 46, 2007: 185; Cuyckens et al. 2014: 199); and (ii) if there are differences and/or similarities in the factors that condition this CC variation in the Late Modern English period and today.

The structure of this article is as follows. Section 2 offers an overview on the evolution of the complementation system of English, focusing on gerundparticipial CCs and the verb REMEMBER in particular. Section 3 presents the aims and methodology adopted, as well as the variables analysed. Section 4 focuses on the results and a discussion of these, followed by Section 5, which summarises the main conclusions and discusses the implications of the findings and avenues for future research.

\section{Background}

Verb complementation, especially clausal verb complementation, has always been an important area of research in English linguistics. Initially, generative and cognitive-functional linguists conducted synchronic studies with a 
148 NEUPHILOLOGISCHE MITTEILUNGEN - I CXXI 2020

The Diachronic Evolution of the Complementation Profile of REMEMBER

from Late Modern to Present-day British English

focus on syntactic issues (for example, the constituent structure of different complementation patterns; cf. Bresnan 1970, 1979) and semantic issues (e.g. the match between a particular verb and certain complementation options; cf. Noonan 2007). These studies have been complemented over the last three decades with diachronic work that has provided an overview of variation and change in the complementation system of English (Cuyckens et al. 2014: 183184; cf. Fischer 1992; Fanego 1996a, 1996b, 1996c, 2004a, 2004b, 2004c, 2007, 2016; Rudanko 1998, 2006, 2010, 2011, 2017; Los 2005, 2015; Rohdenburg 2006, 2007, 2014; De Smet 2007, 2013, 2014; Cuyckens et al. 2014). I will now provide an overview of the diachronic evolution of the complementation system in English, looking in particular at how it affected the verb REMEMBER.

Since Old English times (700-1100), declarative CCs, both expanded (6) and bare ones (7), and bare infinitival CCs (8) have been a part of the English repertoire (Fischer 1992: 313; Traugott 1992: 234-249; Rohdenburg 2014: 156). However, to-infinitival CCs emerged over the course of the Old English period. This construction was formed by an infinitival followed by a prepositional to, originally meaning 'toward', as in (9).

6. Geseođ mine handa \& mine fet,

See my hands and my feet, that I (my)self it am

'See from my hands and feet that it is $P$.

(AECHom I, 5 82.10; cf. Traugott 1992: 238)

7....and cwæđ he wolde wiđsacan his Criste

... and said he intended to-deny his Christ

'And he said he intended to deny his Christ'.

(AELS (Basil) 371; cf. Traugott 1992: 236)

8. He sæde एæt he... wolde fandian hu longe pæt land norpryhte løge 'He said that he.... wanted to-find-out how long that land northwards lay'

(Or 1 1.17.1; cf. Traugott 1992: 242)

9.... ne be nan neod Dearf ne lærde to wyrcanne bæt bæt đu worthest ...nor thee no need not taught to perform that that thou performedst 
149 NEUPHILOLOGISCHE MITTEILUNGEN - I CXXI 2020

The Diachronic Evolution of the Complementation Profile of REMEMBER

from Late Modern to Present-day British English

'... nor did any need teach you to perform what you performed'

(Bo 33.79.16; cf. Traugott 1992: 242)

Furthermore, the early Middle English period also sees the appearance of for to as an infinitival marker (cf. e.g. Cuyckens 1999; De Smet and Cuyckens 2005; De Smet 2007, 2014), as illustrated in (10). During the late $13^{\text {th }}$ and $14^{\text {th }}$ centuries its alternation with the marker to (and in some cases also with the bare infinitival) is free (Fischer 1992: 317; Rissanen 1999: 286).

10. al my walkynge out by nyghte/ Was for t'espye wenches that the dighte. 'all my walking out at night/ Was but to spy on girls he kept outright'1 (CT III.397-8 [2,397-8]; cf. Fischer 1992: 319)

The configuration of the complementation system of English as described above can be illustrated with the complementation profile of REMEMBER. Since it entered the language in the $14^{\text {th }}$ century, and before the emergence of gerund-participial CCs, it could govern the existing types of CCs as follows. In Middle English, the verb REMEMBER followed by to-infinitival CCs conveyed the sense of 'not to forget to do something' (Fanego 1996a: 74), that is, 'remember to do', as in (11). For instance, in (11) the action of the CC is projected into the future and is posterior to the action of remembering.

11. Why ne haddist thow remembred in thyn mynde to takyn hire.

'Why hadn't you remembered in your mind to take her.'

(c.1430 (>1386) CHAUCER Legend Good Women (Cambr.Gg.4.27) (1879) l.2717; cf. OED Online, s.v. "remember” v.1)

Additionally, REMEMBER was available with the meaning 'to remind someone', which is no longer attested in Present-day Standard English (Visser 1963-1973: 2270/2286; OED Online, s.v. “remember" v.1). With this meaning REMEMBER could be complemented by complex to-infinitival CCs, as in (12), 
150 NEUPHILOLOGISCHE MITTEILUNGEN - I CXXI 2020

The Diachronic Evolution of the Complementation Profile of REMEMBER

from Late Modern to Present-day British English

and by for to-infinitival, as in (13). This exemplifies the existence of for toinfinitival CCs in free variation with to-infinitival CCs.

12. Let me remember thee to do this one kindness more for me 'Let me remember you to do this one more kind act for me.'

(1596 T. Nashe, Have with You to Saffron-walden II, [OED]; cf. Visser 19631973: 2286)

13. If a biskop ... wolde remembre hem ...for to kepe certeyn moral vertues 'If a bishop... would remember him... for to keep certain moral virtues.' (c.1449 Pecock, Repressor I, iv, 21, [OED]; cf. Visser 1963-1973: 2286)

On the other hand, when the meaning of REMEMBER was retrospective, that is, 'recall', the verb could be complemented in two ways. Either with finite CCs, as in (14), or via the "so-called accusative-with-infinitive construction", i.e. a present simple to-infinitival CC in a context of extraction, as in (15) (Visser 1963-1973: 2234; Fanego 1996a: 74).

14. Assone therefore as he was risen from deeth agayne, his disciples remembred that he thus sayde. and they beleved the scripture, and the words which Iesus had sayde.

'After he was raised from the dead, his disciples remembered he had said this. and they believed both the Scriptures and what Jesus had said.' (1534 Tyndale The New Testament II, 20; cf. Fanego 1996a: 74)

15. In this yere/ and vpon the .xii. day of Octobre were the Flodes in Thamys/ whiche thynge no man than lyuynge cowed remember ye lyke to be seen. 'In this year, on the 12 of October the floods in the Thames happened, the likes of which no living man could remember to see.'

(1516 Fabyan New Chronicles of England and France 175V. C1; cf. Fanego 1996a: 74)

However, the great revolution in the complementation system of English happened later. This series of changes and developments has been labelled 
the Great Complement Shift, and involves, among others ${ }^{2}$, perhaps one of the most prominent changes in the complementation system of English: the emergence of the gerund-participial as a new non-finite CC in the Early Modern English period (Vosberg 2003: 197, 2009: 212; Fanego 2004b: 8; Rohdenburg 2006: 143; De Smet 2013: 131). The first instances of the gerundparticipial appear in Late Middle English, particularly as objects of subjectcontrol verbs (cf. Fanego 2007: 168; Seoane 2017: 78). They subsequently spread at the expense of the already established complementation options, that is, infinitival and declarative CCs, over several centuries (Rohdenburg 2006: 143; Fanego 2007: 168). I will now give an overview of the development of the gerund-participial as a complement and how it permeated the complementation profile of remember.

Originally, -ing was a "derivational suffix which could be freely added to verb stems to form abstract nouns of action” (Rissanen 1999: 291; cf. Fanego 1996a: 72, 1996c: 98, 1998: 87, 2004b: 7, 2004c: 325, 2007: 167; Vosberg 2003: 197; De Smet 2013: 134; Los 2015: 129). This resulted in what is today known as a gerundial noun, as in (16), in contrast with verbal gerund or gerundparticipial clause, as in (17) (Fanego 2004a: 27, 2007: 167, 2016: 88; Fonteyn et al. 2015: 37).

\section{The exploring of the mountain}

\section{Inviting the twins was a big mistake}

The gerundial noun used to occur after prepositions and behaved like any other noun in Old and Middle English; hence, it could take a variety of

2 Other changes in the complementation system of English include, for example: (i) rivalry between bare and to-infinitival forms (Rohdenburg 2006: 144-5); (ii) the spread of the for...to construction to new environments where only to-infinitival had been possible (De Smet 2013: 4; Seoane 2017: 80); (iii) emergence of the to -ing and into -ing complementation patterns as potential rivals to the to-infinitival pattern (Rudanko 1998: 338, 2006: 36, 2010: 6, 2011: 83, 2012: 222-223, 2015: 139, 2017: 32); (iv) replacement of that declarative CCs after a series of verbs, like ALLOW, which had restricted their complementation to finite CCs, by to-infinitival CCs (Fischer 1992: 268; Vosberg 2009: 212; Los 2015: 149; Fanego 2016: 85). 
dependents such as determiners and of-phrases (Fanego 1996c: 98; 2004a: 27, 2004b: 7, 2004c: 325; De Smet 2013: 134). A complex interplay of factors led to the acquisition of verbal properties by the gerundial noun from Late Middle English (1300-1500) onwards, which gave rise to the Present-day English features that the gerund-participial form has, as listed below (Fanego 1996a: 72, 1996b: 33, 1996c: 98, 1998: 88, 2004a: 28, 2004b: 7, 2004c: 325, 2007: 168, 2016: 88-90; Vosberg 2003: 197; Fonteyn et al. 2015: 38; Los 2015: 132).

i. They can govern an object or a predicative complement (e.g. 'their following the child into England', 'I don't remember being ill').

ii. They can be modified by adverbs or adverbials restricted to co-occurring only with verbs (e.g. 'his quickly remembering to cancel the appointment before they left').

iii. They can be negated by means of the VP-negating particle not (e.g. 'my not remembering').

iv. They can show tense and voice distinctions (e.g. 'of having remembered it' and 'the joy of being remembered').

v. They can take a subject in a case other than the genitive (e.g. 'I remember them going without me').

Even though the first attestations of the gerund-participial date back to Late Middle English, it took several centuries for it to extend across the grammar of English (Fanego 1996a: 73, 2004b: 10, 2007: 168; De Smet 2013: 1, 2014 : 226; Fonteyn et al. 2015: 38). During this expansion, the gerund-participial became available in some environments before others. In Middle English the verbalization of gerundial nouns was largely restricted to prepositional environments and only to instances of gerundial nouns that lacked an explicit subject, as can be seen in (18) (Fanego 1996b: 33, 2004b: 11, 38, 2004c: 326, 2007: 169).

18. yn feblyng be body by moche fastyng 'in weakening the body with too much abstinence' (c.1303 (MS a1400) Handlyng Synne HS 408; cf. Fanego 2004a: 28) The gerund-participial then became available in the remaining environments in Modern English and, in some of them, has only become common in recent 
153 NEUPHILOLOGISCHE MITTEILUNGEN - I CXXI 2020

The Diachronic Evolution of the Complementation Profile of REMEMBER from Late Modern to Present-day British English

times. This is the case with the gerund-participial used for coding non-finite CCs without a specific controller, as in (19). In this example the gerundparticipial CC headed by bringing does not have a specific controller (Fanego 2004a: 28, 2004b: 7, 31, 2007: 169, 185).

19. "I have been telling Barbara that a visit to London entails bringing gifts for friends”, (COLMOBAENG BrE4 1861 Wood East Lynne, 33 [Fiction]; cf. Fanego 2007: 185)

The distribution between the infinitival and the gerund-participial was clear in Late Modern English: the latter used to be restricted mostly to environments in which it followed a preposition, as noted above, and the former only combined with to, which used to be a preposition (Rohdenburg 2003: 206; Fanego 2016: 89). However, this changed when the gerund-participial began to expand and occupy other functions, such as the object of a verb. Instances of this phenomenon were found with precursor verbs such as luue 'love', illustrated in (20). From the middle of the $16^{\text {th }}$ century, gerund-participial CCs were found more and more commonly and after more diverse types of verbs (Fanego 1996a: 72, 2004b: 46, 2004c: 325; Fonteyn et al. 2015: 38; Los 2015: 134). Nevertheless, in complement function, the gerund-participial was also restricted to instances in which its subject was not expressed and was understood to be that of the main clause verb (i.e. co-referential subjects). This can be seen in (20), in which the subject of fasting is the same as that of the main verb love, that is, you.

20. and halde pe in chastite, and iuil langingis do way; luue fasting And hold yourself in chastity and evil longings do away love fasting 'and keep yourself chaste, and get rid of evil desires; love fasting' (MED, a1425 Ben.Rule(1)(Lnsd 378) 8/19; cf. De Smet 2013: 162; Los 2015: 134)

Thus, among the earliest verbs to govern gerund-participial CCs was LOVE and other verbs labelled (following the terminology used by De Smet 2013 and Los 2015) as emotion verbs (e.g. ENJOY, LIKE, LOVE), together with avoidance verbs 
154 NEUPHILOLOGISCHE MITTEILUNGEN - I CXXI 2020

The Diachronic Evolution of the Complementation Profile of REMEMBER

from Late Modern to Present-day British English

(e.g. AVOID, ESCAPE, FOREBEAR, REFRAIN), necessity verbs (e.g. NEED, REQUIRE, WANT) and endurance verbs (e.g. ENDURE, BEAR). The gerund-participial CC diffused through these verbs by way of narrow paradigmatic analogy. In other words, since most of these verbs took "bare abstract nouns denoting or implying an action, event, or situation controlled by the matrix subject” (De Smet 2013: 161) and originally the suffix -ing was added to verbs to form an abstract noun of action, as described above and illustrated in (21) and (22), the gerund-participial CC easily fit and occupied the slot of the bare abstract noun. Thus, gerund-participial CCs began their diffusion from this niche in English grammar (De Smet 2013: 160-161; Los 2015: 136-138).

21. Jake avoids/escapes/fears/risks $\left[_{N P}\right.$ capture/punishment/shipreck] (bare abstract noun) (De Smet 2013: 160-161)

22. [He] escaped drowning verye narrowely (OED, 1560; cf. De Smet 2013: 160-161)

From those verbs, the gerund-participial in object position expanded to other classes of verbs that did not collocate with the bare abstract noun (negative implication verbs, such as DEFER, retrospective verbs, such as REMEMBER, and proposal verbs, such as PROPOSE, among others). They did so supported by different processes, such as semantic analogy, indirect paradigmatic analogy and broad paradigmatic analogy (cf. De Smet 2013: 160-251; Los 2015: 134-138). As a result, gerund-participial CCs have been gaining ground at the expense of to-infinitival CCs after a variety of verb classes (REMEMBER included) since the late $17^{\text {th }}$ century (Fanego 1997: 63, 2004a: 28, 2004b: 10, 39, 2007: 170; Denison 1999: 265; Rohdenburg 2003: 206, 2006: 143; Vosberg 2009: 213; Davies 2012: 57; De Smet 2013: 2, 44, 131; Hilpert and Mair 2015: 185).

The gerund-participial complement extended to families of verbs such as retrospective verbs (e.g. REMEMBER, RECALL, RECOLLECT) and proposal verbs (e.g. PROPOSE, RECOMMEND, SUGGEST). In addition, another relevant aspect of gerund-participial CCs is that they became available both with and 
without an expressed subject, i.e. complex gerund-participial CCs and simple gerund-participial CCs (Los 2015: 136-138).

In fact, it is in the Late Modern English period that we find the first instances of gerund-participial CCS after REMEMBER. These represent cases of both complex gerund-participial CCs, as in (23), and simple gerund-participial CCs, as in (24) (De Smet 2014: 215).

23. The child... only remembered his falling into the sea, not being able to give any account how he returned into the ship. (1688, CEMET; cf. De Smet 2014: 215)

24. (...) about Midnight, when he came Home I heard him swear, he'd make her remember leaving the House. (1724, POB; cf. De Smet 2014: 215)

The gerund-participial pattern was initially tense-neutral and therefore not bound to either past or future reference. This allowed the gerund-participial to acquire and specialise in the expression of the retrospective meaning of REMEMBEr 'recall', in contrast with the prospective orientation of the simple to-infinitival (Fanego 1996a: 77; Vosberg 2003: 200-201). Such specialisation has been maintained in Present-day English. The retrospective gerundparticipial clause is still in complementary distribution with the prospective to-infinitival clause after REMEMBER, as illustrated in (25) and (26) respectively (Cuyckens et al. 2014: 182).

25. I remember reading about it in the newspaper. (Declerck 1991: 511; cf. Cuyckens et al. 2014: 182)

26. He remembered to thank her for everything. (cf. Cuyckens et al. 2014: 182)

During the Modern period the gerund-participial continued its expansion and replaced the infinitival in complement position in other environments (cf. Fanego 2007). Nonetheless, the expansion of the gerund-participial as a 
156 NEUPHILOLOGISCHE MITTEILUNGEN - I CXXI 2020

The Diachronic Evolution of the Complementation Profile of REMEMBER

from Late Modern to Present-day British English

CC did not stop there ${ }^{3}$. It became an available complementation option with verbs which have never governed infinitival CCs (e.g. ENTAIL, FACILITATE, INCLUDE, JUSTIFY and UNDERSTAND, among others). Hence, it also spread at the expense of declarative clauses and noun phrases headed by a nominalised noun. For instance, a gerund-participial CC, illustrated in (27), is said to be an alternative to a declarative CC, as in (28) (Fanego 2007: 185).

27. I cannot for the life of me understand mobilizing demonstrations and demonstrating against your -own country (FROWN 1992 Press Reportage, Ao7 96; cf. Fanego 2007: 185)

28. I cannot remember for the life of me understand that one should mobilize demonstrations... (Adapted from Fanego 2007: 185)

Thus, the emergence of the gerund-participial as a CC did not only mean the replacement of one type of non-finite complement by another, but also the appearance of an alternative to finite clauses (i.e. declarative CCs in particular). This entailed the use of gerund-participial CCs increasing at the expense of both these types of CCs over time. Moreover, such growth of nonfinite CCs in general at the expense of finite CCs has been described as a long-term trend in the English language (Denison 1999: 256; Rohdenburg 2003: 206, 2014: 156, 179; Vosberg 2003: 198; Fanego 2004a: 46, 2007: 185; Cuyckens et al. 2014: 199).

In the case of the verb REMEMBER, and to recapitulate, the addition of the gerund-participial CCs implied a reorganisation of its complementation profile as follows. On the one hand, it created (i) a functional differentiation between the to-infinitival, as in (29), and the gerund-participial patterns, as in (30). On the other hand, there exists (ii) an envelope of variation between gerund-participial and declarative CCs with retrospective temporal relation, example, PROPOSE is a verb that goes against the general tendencies of the Shift, since to-infinitival CCs have been the most common type of complement in the period from 1780-1990, while the use of the gerund-participial CC after this verb has decreased (Saarimäki 2018: 125). 
157 NEUPHILOLOGISCHE MITTEILUNGEN - I CXXI 2020

Laura García-Castro • The Diachronic Evolution of the Complementation Profile of REMEMBER from Late Modern to Present-day British English

that is, between finite and non-finite CCs after REMEMBER with the meaning 'recall' (compare (30) with (31)). Both particularities still characterise the complementation profile of REMEMBER today.

29. I must remember to take a carrier bag and to park a bit closer! (GloWbE GB)

30. I remember reading about it in the newspaper.

31. I remember that I read about it in the newspaper.

Furthermore, the verb REMEMBER today is polysemous, with three distinct meanings, each of them with a different complementation profile (cf. Mair 2006; García-Castro 2020). There is the prospective meaning 'remember to do', whose complementation is restricted to simple to-infinitival CCs (that is, without an expressed subject), as in (29). Another is the retrospective meaning 'recall', complemented by non-finite and finite CCs (as exemplified above in (30) and (31)). Finally, we have the meaning 'bear in mind the fact', complemented only by finite CCs, as in (32). Finite CCs after this meaning can have either a retrospective, simultaneous or prospective temporal relation with the main clause (MC). This latter meaning is introduced here since it has been neglected in diachronic studies dealing with REMEMBER (cf. Mair 2006; Cuyckens et al. 2014).

32. But lets remember these 18 years old are paying for that experience with debt, and for some they need that time to grow otherwise they will not be ready for some employers to employ. (GloWbE GB)

As mentioned in Section 1, Cuyckens et al. (2014) study the envelope of variation between finite and non-finite CCs after REMEMBER meaning 'recall' (as well as REGRET ${ }^{4}$ and DENY) in Late Modern English. The justification for

4 The complementation profile of the verb REGRET in Present-day World Englishes is also surveyed in a recent study using GloWbE (Romasanta 2017). However, Romasanta (2017) does not consider the distribution of CCs in variation but of all CCs in general. Therefore, her results cannot be compared to those in Cuyckens et al. (2014). 
their study is that this type of variation is non-categorical: these clauses co-exist and seem to be used depending on the speaker's preferences and the time period involved. Cuyckens et al. (2014) explore this phenomenon in terms of frequency distribution and a number of variables that might influence the choice. Their study is based on data from the Old Bailey Corpus (OBC, Huber et al. 2012), which contains court transcripts, and the Corpus of Late Modern English Texts (extended version) (CLMETEV, De Smet 2006), which is composed mainly of formal prose (Cuyckens et al. 2014: 186).

As for the variable analysis, they select semantic and structural factors as well as extralinguistic additional factors, such as genre and period, among others (cf. Section 3.2). Some of these factors are selected in light of the Complexity Principle (Rohdenburg 1996, 2006), which is considered by De Smet (2013: 2-3) to be one of the mechanisms that may have delayed the expansion of the gerund-participial and the replacement of other type of CCs, that is finite and to-infinitival CCs.

According to this principle, more explicit grammatical options tend to be favoured in more cognitively complex syntactic environments (e.g. negation, passive structures, long sentences, among other features) (Rohdenburg 1996: 151). As Rohdenburg (1996: 151-152) argues, CC variation may be accounted for by this principle, since the different types of CCs can be classified on a continuum of explicitness (from less to more explicit), as is the case with finite and non-finite CCs. For example, finite declarative CCs are more grammatically explicit (than non-finite CCs) since they must have an expressed subject and they code for tense/mode distinctions, among other features (Cuyckens et al. 2014: 199). Therefore, it follows that structurally complex environments, taking structural complexity as a measure of cognitive complexity, will favour the more explicit option, i.e. finite CCs. Conversely, less complex environments will favour the non-finite alternative (Cuyckens et al. 2014: 198-199). This is in line with Mair's (2006: 222) claim that a high degree of elaboration makes the finite CC option after REMEMBER more likely.

Their findings, in terms of distribution, are in line with the literature on the diachronic development of complementation. As expected, they show an increase in the proportion of non-finite CCS after REMEMBER across 
the two Late Modern English subperiods they consider, as shown in Table 1. Therefore, the expansion of non-finite CCs in detriment to finite CCs is confirmed (Cuyckens et al. 2014: 200).

Table 1. Distribution of finite and non-finite CCs across Late Modern English subperiods.

\begin{tabular}{|c|c|c|c|c|c|c|}
\hline & \multicolumn{2}{|c|}{ Finite CCs } & \multicolumn{2}{|c|}{ Non-finite CCs } & \multicolumn{2}{|c|}{ Total } \\
\hline & No. & $\%$ & No. & $\%$ & No. & $\%$ \\
\hline Early (1710-1780) & 462 & 51.0 & 446 & 49.0 & 908 & 100 \\
\hline Late (1781-1920) & 696 & 24.0 & 2,206 & 76.0 & 2,902 & 100 \\
\hline
\end{tabular}

They perform a binary logistic regression analysis of the examples of the three verbs (REMEMBER, REGRET and DENY) combined ${ }^{5}$, and the results can be summarised as follows. (i) The only semantic factor that significantly predicts the form of the $\mathrm{CC}$ is whether it expresses a state or an event/action. (ii) As for structural factors, TYPE SUBJECT CC and INTERVENING MATERIAL significantly disfavour non-finite complementation. (iii) The speech-based genre, as opposed to the written one, is more favourable to non-finite complementation. And (iv) there appears to be a significantly increasing preference for non-finite CCs over time.

With regard to the Complexity Principle, Rohdenburg's (1996, 2006) earlier findings are strengthened by those of Cuyckens et al. (2014). Not only INTERVENING MATERIAL, but other additional COMPLEXITY factors (e.g. complex CC subjects), have a disfavouring effect on non-finite complementation. However, other features, such as COMPLEXITY CC, favour non-finite CCs. Thus, Cuyckens et al. (2014: 199) conclude that "Rohdenburg's proposed disfavouring effect cannot be generalised to all structural complexity factors, and in that sense, Rohdenburg's Complexity Principle does not apply as generally as commonly held”. More recent studies, such

5 From a total of 5,228 instances in their data sample, 3,810 (73\%) are instances of the verb REMEMBER. Therefore, variable analysis results are likely to be heavily conditioned by the behaviour of finite and non-finite CCs after REMEMBER and can be extrapolated to reflect the favouring and disfavouring features on non-finite complementation after this verb. 
as Pijpops et al. (2018: 538) (who study the alternation between direct and prepositional objects of the verb ZOEKEN 'to search' in Dutch where the preposition naar 'to' introducing the object is optional, like the conjunction that in English, considering the Complexity Principle) also seem to show that the Complexity Principle "should not be interpreted as a blind law, but rather as a general tendency that holds in most, but not all contexts”. These results will be compared with those from the present research in Section 4.

\section{Data and methodology}

\subsection{Data selection}

As discussed in Sections 1 and 2, free variation between finite and non-finite CCs occurs after REMEMBER with the meaning 'recall', something few other verbs allow (e.g. REGRET and FORGET). These CCs always have a retrospective temporal relationship with respect to REMEMBER (cf. Cuyckens et al. 2014: 201-202). This can be seen in (33), where the act of analysing a rather harmless poem about picking blackberries happens before the action of remembering.

33. I remember $\emptyset$ we were analysing a rather harmless poem about picking blackberries. (GloWbE GB)

Finite CCs in competition after REMEMBER are declarative CCs (Huddleston and Pullum et al. 2002: 951-953). They can be either bare declarative CCs, as in (33) above, or expanded declarative ones, as in (34). The difference is brought about by the absence or presence of the complementizer that.

6 Pijpops et al. (2018) also aim at discovering what drives the correlation between complexity and explicitness, as expressed in the Complexity Principle (Rohdenburg 1996). They take into consideration three different viewpoints: (i) that the Complexity Principle is chiefly caused by cognitive processing during language production; (ii) that it is primarily the result of restrictions on the physical language channel; and, (iii) that the correlation emerges primarily due to cognitive comprehension processing. Although this approach is very interesting and should be considered in further research, it falls out of the scope of the present study. 
34. I remember that we were analysing a rather harmless poem about picking blackberries.

Regarding non-finite CCs after REMEMBER with the meaning 'recall', gerundparticipial CCs with or without an explicit subject, as in (35) and (36) respectively, are prevalent nowadays. However, residual instances of toinfinitival CCs, as in (37), can also be found, although very rarely (as expected, cf. Vosberg 2003: 199).

35. I can remember John talking about his various printing and laundry businesses. (GloWbE GB)

36. I remember being awakened around 4am by loud banging. (GloWbE GB)

37. A more natural story we do not remember to have read. (GloWbE GB)

The data used to explore this envelope of variation in the present study were extracted from the Corpus of Global Web-based English (GloWbE; cf. Davies 2013), specifically a 3,000-hit random sample from the BrE section. The data in GloWbE comprise examples of "English as used on the net" (LoureiroPorto 2017: 455) and were retrieved from the Internet in 2012. The corpus thus offers a snapshot of very recent English'? One of the main advantages of GloWbE ${ }^{8}$ is its size: with 1.9 billion words it allows for research into lowfrequency phenomena such as CC variation. By contrast, corpora such as ICE (The International Corpus of English) proved to be too small for this (cf. García-Castro 2018).

Using GloWbE as a source of synchronic data entails having different text types for the periods compared (i.e. court transcripts, formal prose and English as used on the net respectively). However, it is a useful corpus in terms of recency and quantity of the data.

8 While the compilation of GloWbE has been a successful in terms of size, other issues need to be addressed. For example, it is unknown, or difficult to know, which type of speakers (acrolectal, mesolectal, basilectal) are represented and where they are from (cf. Mukherjee 2015: 35). 
The random sample was compiled by retrieving all the hits available for the verb REMEMBER, looking for the forms <remember>, <remembers>, $<$ remembered $>$ and $\langle$ remembering $>$. Then the first 3,00o hits were selected, after the sample had been randomised. Hits were manually pruned of all spurious and non-relevant hits (nominal complements, intransitive patterns, among others, as shown in examples (38) and (39) respectively), leaving 542 instances of REMEMBER meaning 'recall' followed by a CC. These examples were then coded as described in Section 3.2.

38. Well I remember two things that used to frustrate me a lot in my office job. (GloWbE GB)

39. A mnemonic to help you remember: "There's some port left. "(GloWbE GB)

\subsection{Coding of the data}

Each relevant corpus attestation of remember $+\mathrm{CC}$ in which the meaning of remember is 'recall' was entered into an IBM SPSS (Statistical Package for the Social Sciences) Statistics 25.0 (IBM Corp. 2017) database. These hits were then coded for a number of intra-linguistic factors which might determine the CC choice: characteristics of the main clause (MC), characteristic of the CC, and characteristics of the combined structure of the MC and the $\mathrm{CC}$. The selection of potentially significant factors, listed in Table 2, was drawn from those in Cuyckens et al. (2014) ${ }^{9}$. Some adjustments had to be made, particularly in the values in the variables, most of which are conditioned by the nature of my examples.

9 Factors such as MEDIUM and PERIOD were not included in the present study because they do not apply to my data. In the case of time reference, in accordance with Noonan's (2007) classification, and as Cuyckens et al.'s (2014) analysis shows, all instances of CCs following REMEMBER with the meaning 'recall' have an independent temporal relationship with respect to the MC, and for that reason this variable is not useful, in that all CCs under study correspond to one of its values. 
Table 2. List of language-internal variables coded.

\begin{tabular}{|c|c|c|}
\hline Type of variable & Name of variable & Values \\
\hline Semantic & MEANING CC & $\begin{array}{l}\text { Event/Action } \\
\text { State }\end{array}$ \\
\hline \multirow[t]{5}{*}{ Structural factors } & TYPE SUBJECT MC & $\begin{array}{l}\text { Pronoun } \\
\text { Noun Phrase } \\
\text { None }\end{array}$ \\
\hline & TYPE SUBJECT CC & $\begin{array}{l}\text { Complex NP } \\
\text { Other }\end{array}$ \\
\hline & $\begin{array}{l}\text { COMPLEXITY CC IN NO. OF } \\
\text { CONSTITUENTS }\end{array}$ & $\begin{array}{l}\text { Short (0-1) } \\
\text { Medium (2-3) } \\
\text { Long }(4-5)\end{array}$ \\
\hline & INTERVENING MATERIAL & $\begin{array}{l}\text { Presence } \\
\text { Absence }\end{array}$ \\
\hline & VOICE CC VERB & $\begin{array}{l}\text { Active } \\
\text { Passive }\end{array}$ \\
\hline \multirow[t]{2}{*}{ Additional factors } & DENOTATION & $\begin{array}{l}\text { Same } \\
\text { Different }\end{array}$ \\
\hline & ANIMACY SUBJECT CC & $\begin{array}{l}\text { Animate } \\
\text { Inanimate }\end{array}$ \\
\hline
\end{tabular}

Starting with semantic factors, I only use the variable MEANING OF THE CC, with the values event/action, as in (40), where the verb of the CC refers to an action (exposing) and state, as in (41), where the verb of the CC refers to the state of being a certain way at the age of two (the same as in Cuyckens et al. 2014: 188-189). As regards the other two semantic factors that they explore, i.e. the meaning of the matrix verb and time reference, these are not useful in determining variation. The reasons for this are that (a) in the pruning of the data I had already selected those instances in which REMEMBER means 'recall' and (b), the values of the variable TIME REFERENCE appear to correspond with the values in the variable TYPE OF CC and thus cannot influence the variation.

40. I don't remember the BBC exposing the government over the Health \&; Social Care bill's passage - silence! (GloWbE GB) 
164 NEUPHILOLOGISCHE MITTEILUNGEN - I CXXI 2020

The Diachronic Evolution of the Complementation Profile of REMEMBER

from Late Modern to Present-day British English

41. I'm heterosexual but I don't remember being that as a two year old either. (GloWbE GB)

Some of the structural variables had their values adjusted, this for a number of reasons. Within the variable TYPE OF SUBJECT MC, the initial values pronoun I, pronoun II and pronoun III were grouped into the value pronoun in order to facilitate statistical testing. The remaining values and the values for the variable TYPE SUBJEC C CC remained the same. Following Cuyckens et al. (2014), the value complex NP includes subjects with two nouns or a noun with a postmodifier, as illustrated in (42) and (43) below. The value other includes the remaining possibilities.

42. I remember President Chirac saying after a particularly dull intervention by a Finnish foreign minister at the Nice European summit, which he was chairing, that sometimes people miss a very good opportunity to shut up. (GloWbE GB)

43. I remember once, one of the children who had been very, very rejecting of me, came over and sniffed the air. (GloWbE GB)

To measure the complexity of the CC predicate, I expanded Cuyckens et al.'s (2014) values. While their values only accounted for predicates with zero, one or two constituents, I found up to five constituents in some examples of my data, as illustrated in (44), where each constituent is underlined.

44. I remember on set once looking at the pictures closely trying to figure out if she had even one blemish on her skin. (GloWbE)

As for the variable vOICE CC VERB, I eliminated the value copular since it could cause collinearity problems between this variable and the variable MEANING CC, particularly with the value state. Finally, the additional 
165 NEUPHILOLOGISCHE MITTEILUNGEN - I CXXI 2020

Laura García-Castro • The Diachronic Evolution of the Complementation Profile of REMEMBER

from Late Modern to Present-day British English

variables DENOTATION ${ }^{10}$, ANIMACY SUBJECT CC and INTERVENING MATERIAL (see (45) for an example of intervening material between the MC and the CC) did not suffer modification of their values.

45. I can remember so clearly navigating dark empty streets, knowing that an important mission lay ahead for me. (GloWbE GB)

\subsection{Statistical analysis}

In order to detect which variables are really determinant in CC variation and to gauge their impact, I use a regression model. Binary logistic regression analysis is a statistical test that predicts the choice between two variants (the values of the dependent variable) based on a series of explanatory factors (i.e. each of the variables presented in Section 3.2; Field 2009: 265). This analysis yields a value "that reflects the chances of one outcome compared with the other outcome for a given combination of values of the predictors" (Levshina 2015: 253). In the case here, TYPE OF CC is the dependent variable and its values are finite CCs and non-finite CCs. The results of the regression analysis (namely, predicted odds) show whether the independent variables and their values favour or disfavour non-finite CCs (the outcome, in statistical terms). The key value for the interpretation of logistic regression analysis is the odds ratio (OR) value. This value is an indicator of the change in odds that results from a unit change in the predictor, and can be interpreted as follows (Field 2009: 270-271; Levshina 2015: 260):

- A value higher than 1 indicates that as the predictor increases, the odds of the outcome occurring increase (the outcome being one of the values of the dependent variable).

- A value lower than 1 it indicates that as the predictor increases, the odds of the outcome occurring decrease.

10 Denotation refers to whether the MC subject and CC subject denote different or the same entities. 
Using the IBM SPSS Statistics 25.0 (IBM Corp. 2017) software package, I followed the customary steps to obtain an adequate regression model. Thus, I began by establishing a model that included all the potentially relevant language internal variables ${ }^{11}$. Subsequently, the model was refined (where necessary) by excluding non-suitable variables, that is, those that showed collinearity with another variable or quasi-complete separation from the dependent variable. The model and its results are presented in Section 4.2.

\section{Results}

\subsection{Frequency distribution}

Table 3 sets out the frequency distribution of finite and non-finite CCs in GloWbE GB, which shows a clear preference for non-finite CCs. These constitute almost three quarters of all the instances of REMEMBER meaning 'recall' followed by a CC $(74.5 \%)$. These results will be discussed further in Section 4.3, below.

Table 3. Distribution of finite and non-finite CCs in GloWbE GB.

\begin{tabular}{cccccc}
\hline & Finite & \multicolumn{2}{c}{ Non-finite } & \multicolumn{2}{c}{ Total } \\
\hline No. & $\%$ & No. & $\%$ & No. & $\%$ \\
\hline 138 & 25.5 & 404 & 74.5 & 542 & 100 \\
\hline
\end{tabular}

\subsection{Binary logistic regression analysis}

Turning to language-internal factors, one of the variables presented in section 3.2 cannot be introduced in the binary logistic regression analysis since it does not comply with the chi-square assumptions (cf. Field 2009: 692). This is INTERVENING MATERIAL: As shown in Table 4, 10 cells (83.3\%) have an expected frequency below 5 and 7 cells have expected frequencies below 1. 
Although this distribution cannot be statistically tested, we can observe that intervening material is more common in finite CCs (in $4.3 \%$ of finite CCs there is intervening material between the $\mathrm{MC}$ and the $\mathrm{CC}$ ) than in non-finite $\mathrm{CCs}$ (only $1 \%$ of non-finite CCs occur in environments with intervening material between the MC and the $\mathrm{CC}$ ). This could be related to the Complexity Principle (1996, 2006), since intervening material seems to be more common in the case of finite CCs, that is, in more grammatically explicit options, while it is less common when non-finite CCs are used.

Table 4. Intervening material in number of words.

\begin{tabular}{|c|c|c|c|c|c|}
\hline \multicolumn{2}{|c|}{ Words } & \multicolumn{2}{|c|}{ Finite } & \multicolumn{2}{|c|}{ Non-finite } \\
\hline & & No. & $\%$ & No. & $\%$ \\
\hline \multirow[t]{2}{*}{0} & No. & 132 & 95.7 & 400 & 99.0 \\
\hline & Expected & 135.5 & & 396.5 & \\
\hline \multirow[t]{2}{*}{1} & No. & 2 & 1.4 & 0 & 0 \\
\hline & Expected & 0.5 & & 1.5 & \\
\hline \multirow[t]{2}{*}{2} & No. & 2 & 1.4 & 3 & 0.7 \\
\hline & Expected & 1.3 & & 3.7 & \\
\hline \multirow[t]{2}{*}{5} & No. & 0 & 0.0 & 1 & 0.2 \\
\hline & Expected & 0.3 & & 0.7 & \\
\hline \multirow[t]{2}{*}{7} & No. & 1 & 0.7 & 0 & 0 \\
\hline & Expected & 0.3 & & 0.7 & \\
\hline \multirow[t]{2}{*}{10} & No. & 1 & 0.7 & 0 & 0 \\
\hline & Expected & 0.3 & & 0.7 & \\
\hline & tal & 138 & 100 & 404 & 100 \\
\hline
\end{tabular}

Therefore, all variables but INTERVENING MATERIAL were included in the binary logistic regression model. Before I fitted the model, I ran a collinearity test in the form of a linear regression analysis. This analysis showed no signs of collinearity between the remaining independent predictors in the tolerance values, variance inflation factor, condition indexes or variance proportion values (cf. Field 2009: 273). All variables were included in the binary logistic regression model, as shown in Table 5. 
Table 5. Odds ratio values and significance of the variables in the model (* significant at $p<$ $0.05,{ }^{* *}$ significant at $p<0.01,{ }^{* * *}$ significant at $\left.p<0.001\right)$.

\begin{tabular}{|c|c|c|}
\hline \multicolumn{3}{|c|}{ Odds ratios (ORs) } \\
\hline (Intercept) & Not significant & \\
\hline \multicolumn{3}{|c|}{ MEANING CC (default event/action) } \\
\hline State & 0.415 & $* *$ \\
\hline \multicolumn{3}{|c|}{ TYPE SUBJECT MC (default pronoun) } \\
\hline Noun phrase & Not significant & \\
\hline None & Not significant & \\
\hline \multicolumn{3}{|c|}{ TYPE SUBJECT CC (default complex NP) } \\
\hline Other & Not significant & \\
\hline \multicolumn{3}{|c|}{ DENOTATION (default same) } \\
\hline Different & 0.165 & $* * *$ \\
\hline \multicolumn{3}{|c|}{ CC SUBJECT ANIMACY (default animate) } \\
\hline Inanimate & 0.498 & * \\
\hline \multicolumn{3}{|c|}{ COMPLEXITY CC IN NO. CONSTITUENTS (default short) } \\
\hline Medium & Not significant & \\
\hline Long & Not significant & \\
\hline \multicolumn{3}{|c|}{ VOICE CC VERB (default active) } \\
\hline Passive & Not significant & \\
\hline Constant & 25.527 & $* * *$ \\
\hline
\end{tabular}

Firstly, as indicated in Table 5, some variables are not significant, and thus they do not condition the choice between finite and non-finite CCs in the present dataset. These are TYPE SUBJECT MC, TYPE SUBJECT CC, COMPLEXITY CC IN NO. CONSTITUENTS and VOICE CC VERB. In other words, none of the factors that measure structural complexity are significant. As for the significant results, that is, those factors which influence CC variation, odds ratios are lower than 1. As noted in Section 3.3, this means that they disfavour the odds of the outcome happening, in this case non-finite CCs. For the variable MEANING CC, the value state, with respect to the default event/action, decreases the odds of non-finite CCs by a factor of 0.415 (i.e. by 58.5\%). In terms of DENOTATION, this variable has a robustly disfavouring effect on complementation choice: if the value is different, the odds for non-finite CCs decrease by a factor of 0.165 , 
i.e. by $83.5 \%$. Another disfavouring effect is CC SUBJECT ANIMACY=inanimate (ORs: 0.498, i.e. $51.2 \%$ ).

\subsection{Discussion of results}

This section discusses the findings of the present study. Furthermore, it aims to compare these with previous claims made in the literature on the evolution of the clausal complementation system in English, the complementation profile of the verb REMEMBER and the causes conditioning CC variation.

Figure 1 illustrates the diachronic evolution of the distribution of finite and non-finite CCs (in \%) by comparing the results of Cuyckens et al. (2014). The two subperiods within the Late Modern English period (1710-1780, 17811920) that they established are complemented with the representation of synchronic BrE data (2012) found in GloWbE.

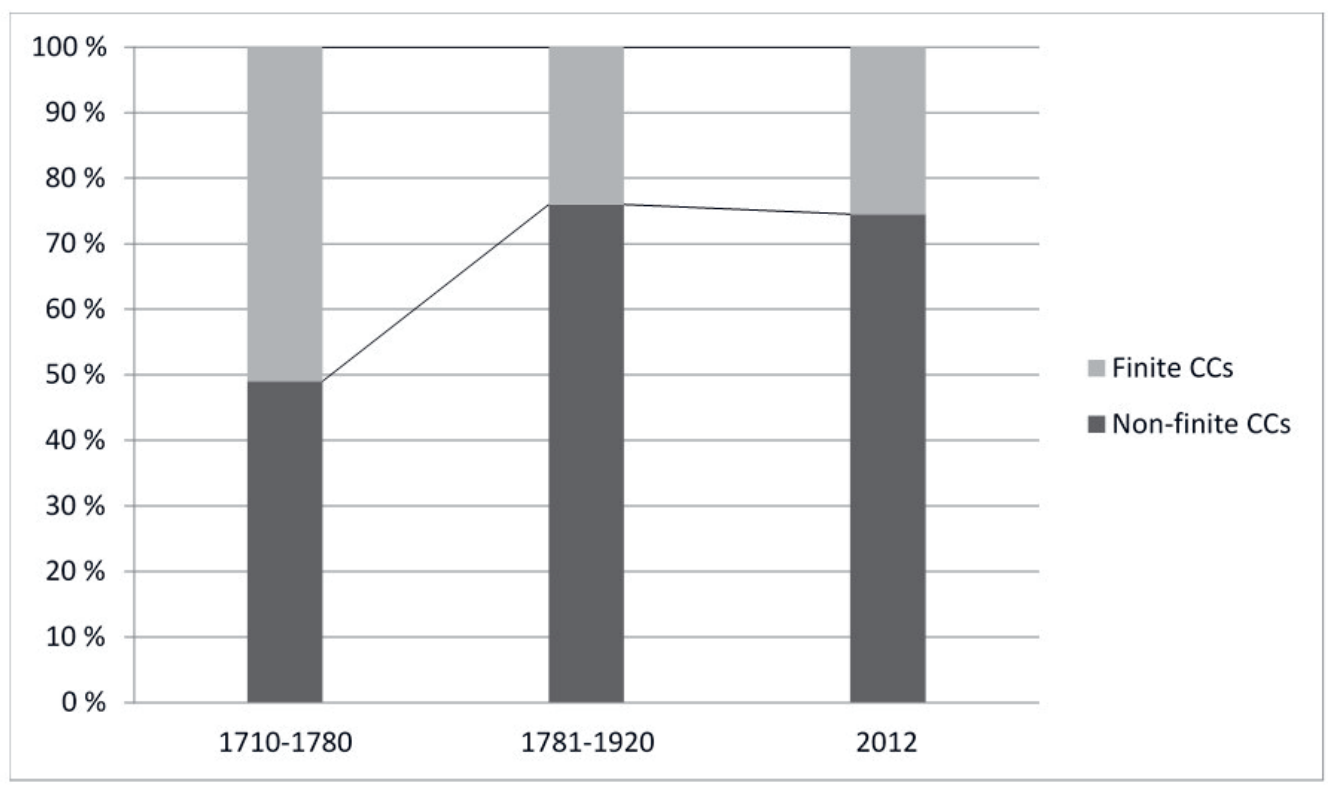

Figure 1. Diachronic evolution of the distribution of finite and non-finite CCs after REMEMBER with the meaning 'recall' $\left(x^{2}=244.8, d f=2, p=0.000\right)$

As shown in Figure 1 (and tables 1 and 3 in sections 2 and 4.1 respectively), the distribution of finite and non-finite CCs has barely changed since the latter part of the Late Modern English period. Moreover, it can be seen that there is no increase of non-finite complementation as might be expected based 
170 NEUPHILOLOGISCHE MITTEILUNGEN - I CXXI 2020

Laura García-Castro • The Diachronic Evolution of the Complementation Profile of REMEMBER

from Late Modern to Present-day British English

on the alleged tendency in the English language of non-finite CCs to expand at the expense of finite CCs (cf. Section 2; Denison 1999: 256; Rohdenburg 2003: 206: 2014: 156, 179; Vosberg 2003: 198; Fanego 2004a: 46, 2007: 185; Cuyckens et al. 2014: 199). On the contrary, there is a significant decrease (at $\mathrm{p}<0.05$, as shown in Figure 1) in the proportion of non-finite CCs, from $76.0 \%$ in the latter subperiod of Late Modern English to $74.5 \%$ in the 2012 data. Thus, after a sharp increase between the Late Modern English subperiods, the expansion of non-finite CCs appears to have stalled in the last century. Hence, these findings are in conflict with the trend described in the literature and which was corroborated by Cuyckens et al.'s (2014) results. It remains to be seen, though, whether this is a singularity of the complementation profile of REMEMBER or if non-finite CCs have reached a plateau. If this were the case, the distribution of finite and non-finite CCs in competition could have stabilised across the complementation system of English.

As for language-internal factors, the binary logistic regression analysis reveals that non-structural factors are determinant in CC variation, while none of the structural factors, which were used to measure cognitive complexity, are significant. Therefore, it seems that the Complexity Principle $(1996,2006)$ does not have an effect on the distribution of CCs in competition in the dataset corresponding to Present-day BrE. As Cuyckens et al. (2014: 199) and Pijpops et al. (2018: 538) mentioned, Rohdenburg's (1996, 2006) Complexity Principle may not apply as generally as has been supposed, and this envelope of variation could be a case in point.

Those factors that are significant and thus disfavour non-finite complementation are also significant in Cuyckens et al. (2014), namely MEANING CC: state, DENOTATION: different and ANIMACY SUBJECT CC: different. This seems to indicate that some factors have been conditioning the variation over a span of at least 300 years, that is, since the beginning of the $18^{\text {th }}$ century until the second decade of the $21^{\text {st }}$ century. The only difference would concern the structural factors that are significant in their study (TYPE SUBJECT MC, TYPE OF SUBJECT CC, COMPLEXITY CC, INTERVENING MATERIAL AND VOICE CC VERB) but not in the present one. 
As Cuyckens et al. (2014: 198) note, the fact that DENOTATION= different and ANIMACY SUBJECT CC= inanimate disfavour non-finite CCs is not unexpected. This is due to the nature of simple gerund participial CCs, which make up the majority of the non-finite CCs in the sample, as illustrated in Table 6.

Table 6. Distribution of types of non-finite CCs in GloWbE GB.

\begin{tabular}{lll}
\hline & No. & $\%$ \\
\hline Simple to-infinitival & 2 & 0.5 \\
Complex to-infinitival & 1 & 0.2 \\
Simple gerund-participial & 278 & 30.4 \\
Complex gerund-participial & 123 & 68.8 \\
\hline Total & $\mathbf{4 0 4}$ & $\mathbf{1 0 0}$ \\
\hline
\end{tabular}

In the case of simple gerund participial CCs, the subject of the CC is the same as that of the MC, and thus is left unexpressed, as illustrated in (46).

46. (...) and I tried to remember ever $\emptyset$ loving him. (GloWbE GB)

Moreover, since the action of REMEMBER can only be carried out by an animate entity, inanimate CC-subjects always differ from the subject of the MC. Therefore, as explained above, a different denotation disfavours nonfinite complementation in my dataset. As shown in Table 7, this feature is far less common in non-finite CCs (5.5\%) than in finite CCs (29.5\%), although it does happen, as in (47), but never in simple non-finite CCs, that is, when the subject is not expressed.

47. Maybe “app” is a generic term, although I don’t remember it being widely used before the iPhone came out. (GloWbE GB) 
Table 7. Distribution of finite and non-finite CCs in the variable CC subject animacy.

\begin{tabular}{|l|l|l|l|l|}
\hline & \multicolumn{3}{|c|}{ Finite } & \multicolumn{2}{c|}{ Non-finite } \\
\hline Animate & No. & $\%$ & No. & $\%$ \\
\hline Inanimate & 97 & 70.5 & 381 & 94.5 \\
\hline Total & 41 & 29.5 & 23 & 5.5 \\
\hline
\end{tabular}

Therefore, taking into consideration these findings and the larger proportion of simple gerund-participial CCs which might be influencing the results of the binary logistic regression model, it would be interesting to compare only cases of finite and non-finite CCs in which the denotation is different, that is, excluding simple gerund-participial CCs and finite CCs with same denotation. This leads to the distribution as set out in Table 8. Here, finite CCs are slightly more common and the distribution is more balanced than when considering all finite and non-finite CCs together. This sample, however, is small and thus in future research we should expand the database and replicate the binary logistic regression analysis in order to see whether the same factors condition variation in this case as well, or whether simple gerund participial CCs were biasing the results.

Table 8. Distribution of finite and non-finite CCs with a different denotation between the MC and the CC subjects.

\begin{tabular}{|c|c|c|c|c|c|c|}
\hline & \multicolumn{2}{|c|}{ Finite } & \multicolumn{2}{|c|}{ Non-finite } & \multicolumn{2}{|c|}{ Total } \\
\hline & No. & $\%$ & No. & $\%$ & No. & $\%$ \\
\hline Denotation: different & 107 & 46.5 & 122 & 53.5 & 229 & 100 \\
\hline
\end{tabular}

Based on these results, the following conclusions can be drawn. First, the expansion of gerund-participial CCs seems to have halted in the last century, since the proportion is fairly similar at the end of the Late Modern English period and today. Thus, and as a consequence, the alleged general trend in the English language towards the expansion of non-finite CCs at the expense of finite CCs is not corroborated by my data. Second, structural factors, and hence the Complexity Principle (Rohdenburg 1996, 2006), do not seem to 
173 NEUPHILOLOGISCHE MITTEILUNGEN - I CXXI 2020

The Diachronic Evolution of the Complementation Profile of REMEMBER

from Late Modern to Present-day British English

be major determinants in CC variation after REMEMBER meaning 'recall' today, although some of these factors conditioned the variation in the Late Modern English period. On the other hand, though, non-structural factors, particularly CC MEANING, DENOTATION and ANIMACY SUBJECT CC, have been determinants of CC variation over at least the last three hundred years, and until the present time. Finally, some of these results might have been expected, taking into consideration the nature of simple non-finite CCs. They are the most common type of CC in the data sample and are characterised by (i) not having an expressed subject because it is the same as that of the MC, and (ii) never having an inanimate subject, since the act of remembering can only be performed by an animate entity. Therefore, it would be interesting to investigate whether the same language-internal factors condition the choice if only finite and non-finite CCs with a different denotation were subject to analysis.

\section{Conclusion}

In this paper I have explored the envelope of variation between finite and non-finite CCs after REMEMBER (with the meaning 'recall') in Present-day BrE. I have done so in order to establish the synchronic situation of this case of grammatical variation and to assess the diachronic evolution since the Late Modern English period. Following a two-step approach, I have examined frequency distribution of the two types of CCs in competition, and performed a binary logistic regression analysis, which has revealed which factors disfavour non-finite complementation in the British section of GloWbE. The observed preferences have been considered (i) in relation to the alleged tendency in the English language for non-finite CCs to expand at the expense of finite CCs, (ii) in comparison with Cuyckens et al.'s (2014) results for the Late Modern English period, both in terms of frequency distribution and factors conditioning the variation, and (iii) in light of Rohdenburg's (1996, 2006) Complexity Principle.

This study shows that BrE exhibits a larger proportion of non-finite complementation, an ultimate result of the emergence and expansion of gerund-participial CCs which infiltrated the complementation profile of REMEMBER as part of the Great Complement Shift. However, a comparison 
174 NEUPHILOLOGISCHE MITTEILUNGEN - I CXXI 2020

The Diachronic Evolution of the Complementation Profile of REMEMBER

from Late Modern to Present-day British English

between the Present-day BrE distribution of finite and non-finite CCs and that of the Late Modern English subperiods reflects a halt in the increase of non-finite complementation after the verb REMEMBER with the meaning 'recall', whose proportion has stabilised at around 75\% over the last century. Therefore, these results seem to imply that, at least in the complementation profile of REMEMBER, the general trend attested in English towards the growth of non-finite CCs at the expense of finite CC is not confirmed in Present-day $\mathrm{BrE}$ as represented in GloWbE. As for language internal factors conditioning CC variation, structural factors, that is, those related to the Complexity Principle, are not determinant in my dataset and only non-structural factors such as MEANING CC, DENOTATION and ANIMACY SUBJECT CC, seem to condition the choice in Present-day BrE. These non-structural factors were also determinant in this envelope of variation in Late Modern English, and at least two of them (DENOTATION and ANIMACY SUBJECT CC) appear to be closely related to the nature of the most common type of CC in this envelope of variation: simple non-finite CCs, that is, CCs in which their subject is left unexpressed because it is the same as that of the MC.

Thus, the current analysis is partially at odds with earlier claims as to the distribution, the evolution of this distribution, and the factors that are expected to influence CC choice (structural factors based on the Complexity Principle). However, the analysis here has included very recent data from electronic sources, which combined with the results of Cuyckens et al. (2014) has led to a comprehensive synchronic and diachronic study on the complementation profile of the verb REMEMBER with the retrospective meaning 'recall'. Nonetheless, further work is needed to broaden the scope of research into synchronic studies on clausal complementation which will also lead to diachronic comparisons in the distribution of CC. Studies of this kind would allow us to see (i) whether the trend for non-finite complementation over finite complementation is still strong with other verbs or if distribution has stabilised as is the case here, and (ii) whether the same or different language internal features, structural and/or non-structural, condition CCchoice across the complementation of different predicates. Furthermore, taking into consideration the process and results of this study, it could be replicated in different ways. For example, the data set for Present-day English 
175 NEUPHILOLOGISCHE MITTEILUNGEN - I CXXI 2020

Laura García-Castro • The Diachronic Evolution of the Complementation Profile of REMEMBER from Late Modern to Present-day British English

should be expanded to make sure that the results are not conditioned by the size of the sample. Moreover, CCs with the same denotation as the MC should be excluded, in order to check that simple gerund-participial CCs are not influencing the results and preventing other potentially determinant factors from revealing their true impact. $\mathbf{N}$

LAURA GARCÍA-CASTRO

UNIVERSITY OF VIGO 
176 Laura García-Castro • The Diachronic Evolution of the Complementation Profile of REMEMBER from Late Modern to Present-day British English

\section{Bibliography}

BRESNAN, Joan. 1970. On

complementizers: Toward a syntactic theory of complement types.

Foundations of Language 6 (3): 297321.

BRESNAN, Joan. 1979. Theory of complementation in English syntax. New York: Garland.

CUYCKENS, Hubert. 1999.

Grammaticalisation in the English Prepositions to and for. Cognitive Perspectives on Language, ed. Barbara Lewandowska-Tomaszczyk. 151-161. Frankfurt am Main: Peter Lang. CUYCKENS, Hubert, Frauke D'hoedt and Benedikt Szmrecsanyi. 2014. Variability in Verb Complementation in Late Modern English: Finite vs. Non-finite Patterns. Late Modern English Syntax, ed. Marianne Hundt. 182-203. Cambridge; New York: Cambridge University Press. https:// doi.org/10.1017/ cbo9781139507226.014

DAVIES, Mark. 2012. Recent Shifts with Three Nonfinite Verbal Complements in English: Data from the 100-millionword TIME Corpus (1920s-2000s). The Verb Phrase in English: Investigating Recent Language Change with Corpora, eds. Bas Aarts, Joanne Close, Geoffrey Leech and Sean Wallis. 46-67. Cambridge: Cambridge University Press. https://doi. org/10.1017/cbog781139060998.004 DAVIES, Mark. 2013. Corpus of Global Web-Based English: 1.9 Billion Words from Speakers in 20 Countries (GloWbE). http://corpus.byu.edu/ glowbe. Accessed ADD DATE.
DE SMET, Hendrik compiler. 2006. The Corpus of Late Modern English Texts (Extended Version) (CLMEVET). Department of Linguistics, University of Leuven. https://perswww. kuleuven.be/ uoo44428/. Accessed ADD DATE.

DE SMET, Hendrik. 2007. For ... toinfinitives as Verbal Complements in Late Modern and Present-day English: Between Motivation and Change. English Studies 88 (1): 67-94. https://doi. org/10.1080/00138380601042766

DE SMET, Hendrik. 2013. Spreading Patterns: Diffusional Change in the English System of Complementation. Oxford: Oxford University Press. https://doi.org/10.1093/978019981275 2.001.0001

DE SMET, Hendrik. 2014. Constrained Confusion: The Gerund/Participle Distinction in Late Modern English. Late Modern English Syntax, ed. Marianne Hundt. 224-238. Cambridge: Cambridge University Press. https://doi.org/10.1017/ CBO9781139507226.017

DE SMET, Hendrik and Cuyckens, Hubert. 2005. Pragmatic Strengthening and the Meaning of Complement Constructions: The Case of like and love with the To-Infinitive. Journal of English Linguistics 33 (1): 3-34. https://doi. org/10.1177/0075424204273959

DECLERCK, Renaat. 1991. A comprehensive descriptive grammar of English. Tokyo: Kaitakusha.

DENISON, David. 1999. Syntax. 17761997, Vol. 4 of The Cambridge History of the English Language, ed. Suzanne 
Romaine. 92-329. Cambridge: Cambridge University Press. https:// doi.org/10.1017 CHOL9780521264778.004.

FANEGO, Teresa. 1996a. On the Historical Development of English Retrospective Verbs. Neuphilologische Mitteilungen 97 (1): 71-79.

FANEGO, Teresa. 1996b. The Development of Gerunds as Objects of Subjectcontrol Verbs in English (1400-1760). Diachronica 13 (1): 29-62. https://doi. org/10.1075/dia.13.1.03fan

FANEGO, Teresa. 1996c The Gerund in Early Modern English: Evidence from the Helsinki Corpus. Folia Linguistica Historica 17 (1-2): 97-152. https://doi. org/0.1515/flih.1996.17.1-2.97

FANEGO, Teresa. 1998. Developments in Argument Linking in Early Modern English Gerund Phrases. English Language and Linguistics 2 (1): 87119. https://doi.org/10.1017/ $\underline{S 1360674300000708}$

FANEGO, Teresa. 2004a. Is Cognitive Grammar a Usage-based Model? Towards a Realistic Account of English Sentential Complements. Miscelánea: A Journal of English and American Studies 29: 23-58. Special Issue on Language and Linguistics containing the plenary lectures from ESSE7 (Seventh International Conference of the European Society for the Study of English), University of Zaragoza, 8-12 September 2004.

FANEGO, Teresa. 2004b. On Reanalysis and Actualization in Syntactic Change: The Rise and Development of English Verbal Gerunds. Diachronica 21 (1): 5-55. https://doi.org/10.1075/ dia.21.1.03fan

FANEGO, Teresa. 2004c. Some Strategies for Coding Sentential Subjects in English: From Exaptation to Grammaticalization. Studies in
Language 28 (2): 321-361. https://doi. org/10.1075/sl.28.2.03fan

FANEGO, Teresa, compiler. 2004-2007. A Corpus of Late Modern British and American English Prose (COLMOBAENG). http://www.uscteresafanego.es/research.html. Accessed ADD DATE.

FANEGO, Teresa. 2007. Drift and the Development of Sentential Complements in British and American English from 1700 to the Present Day. 'Of Varying Language and Opposing Creed': New Insights into Late Modern English, eds. Javier Pérez-Guerra, Dolores GonzálezÁlvarez, Jorge L. Bueno-Alonso and Esperanza Rama-Martínez. 161-235. Bern: Peter Lang.

FANEGO, Teresa. 2016. The Great Complement Shift Revisited: The Constructionalization of ACC-ing Gerundives. Functions of Language 23 (1): 84-119. https://doi.org/10.1075/ fol.23.1.05 fan

FIELD, Andy P. 2009. Discovering Statistics Using SPSS: (and Sex and Drugs and Rock ' $n$ ' Roll). 3rd edn. Thousand Oaks, Los Angeles, CA: SAGE Publications. https://doi. org/10.1348/000709906x100611 FISCHER, Olga. 1992. Syntax. In 10661476, Vol. 2 of The Cambridge History of the English Language, ed. Norman Blake. 207-408. Cambridge: Cambridge University Press. https:// doi.org/CHOL9780521264754.005 FONTEYN, Lauren, Hendrik De Smet and Liesbet Heyvaert. 2015. What It Means to Verbalize: The Changing Discourse Functions of the English Gerund. Journal of English Linguistics 43 (1): 36-6o. https://doi. org/10.1177/0075424214564365 
GARCÍA-CASTRO, Laura. 2018. Variation in Verbal Complementation Patterns in Nativised Varieties of English: The Case of REMEMBER in Indian English. Taking Stock to Look Ahead: Celebrating Forty Years of English Studies in Spain, eds. María Fernández San Miguel and ClausPeter Neuman. 207-213. Zaragoza: Prensa Universitaria de la Universidad de Zaragoza.

GARCÍA-CASTRO, Laura. 2020. Finite and non-finite complement clauses in postcolonial Englishes. World Englishes 39: 411-426. https://doi. org/10.1111/weng.12481.

HILPERT, Martin and Christian Mair. 2015. Grammatical Change. The Cambridge Handbook of English Corpus Linguistics, eds. Douglas Biber and Randi Reppen. 180-200. Cambridge: Cambridge University Press. https://doi.org/10.1017/ CBO9781139764377.011

HUBER, Magnus, Magnus Nissel, Patrick Maiwald and Bianca Widlitzki. 2012. The Old Bailey Corpus. Spoken English in the 18th and 19th centuries. www. uni-giessen.de/oldbaileycorpus. Accessed August 19, 2018.

HUDDLESTON, Rodney and Geoffrey K. Pullum, in collaboration with Laurie Bauer, Betty Birner, Ted Briscoe, Peter Collins, David Denison, David Lee, Anita Mittwoch, Geoffrey Nunberg, Frank Palmer, John Payne, Peter Peterson, Lesley Stirling and Gregory Ward. 2002. The Cambridge Grammar of the English Language. Cambridge: Cambridge University Press. https://doi. org/10.1017/9781316423530.001 IBM Corp. Released 2017. "IBM SPSS Statistics for Windows”, version 25.0. Armonk, NY: IBM Corp. https://www. ibm.com/analytics/us/en/spss/spss- statistics-version/. Accessed August 16, 2018.

LEVSHinA, Natalia. 2015. How to do Linguistics with R: Data Exploration and Statistical Analysis. Amsterdam: John Benjamins. https://doi. org/10.1075/Z.195.website Los, Bettelou. 2005. The Rise of the ToInfinitive. Oxford: Oxford University Press.

Los, Bettelou. 2015. A Historical Syntax of English. Edinburgh Textbooks on the English Language. Edinburgh: Edinburgh University Press.

LOUREIRO-PORTO, Lucía. 2017. ICE vs GloWbE: Big Data and Corpus Compilation. World Englishes 36 (3): 448-470. https://doi.org/10.1111/ weng.12281

MAIR, Christian. 2006. Nonfinite Complement Clauses in the Nineteenth Century: The Case of remember. Nineteenth-century English: Stability and Change, eds. Merja Hytö, Mats Rydén and Erik Smitterberg. 215-228. Cambridge: Cambridge University Press. https:// doi.org/10.1017/ CBO9780511486944.009

NOONAN, Michael. 2007. Complementation. Complex Constructions, Vol. 2 of Language Typology and Syntactic Description, ed. Timothy Shopen. 52-150. 2nd edn. Cambridge: Cambridge University Press. https://doi.org/10.1017/ CBO9780511619434.002

MUKHERJEE, Joybrato. 2015. Response to Mark Davies and Robert Fuchs: Expanding horizons in the study of World Englishes with the 1.9 billion word Global Web-based English Corpus (GloWbE). English WorldWide 36 (1): 34-37. https://doi. org/10.1075/eww.36.1.02muk 
OED (The Oxford English Dictionary) Online. 2017. S.v. "remember," v.1. http://www.oed.com/viewdictionary/ Entry/162133. Accessed November 28, 2017.

PIJPOPS, Dirk, Dirk Speelman, Stefan Grondelaers and Freek Van de Velde. 2018. Comparing Explanations for the Complexity Principle. Evidence from Argument Realization. Language and Cognition 10 (3): 514-543. https://doi. org/10.1017/langcog.2018.13

RISSANEN, Matti. 1999. Syntax. 17761997, Vol. 4 of The Cambridge History of the English Language, ed. Roger Lass. 187-331. Cambridge: Cambridge University Press. https://doi. org/10.1017/ CHOL9780521264761.005

ROHDENBURG, Günter. 1996. Cognitive Complexity and Increased Grammatical Explicitness in English. Cognitive Linguistics 7 (2): 149-182. https://doi.org/10.1515/ cogl.1996.7.2.149

ROHDENBURG, Günter. 2003. Cognitive Complexity and horror aequi as Factors Determining the Use of Interrogative Clause Linkers in English. Determinants of Grammatical Variation in English, eds. Günter Rohdenburg and Britta Mondorf. 205-249. Berlin; New York: De Gruyter Mouton. https://doi. org/10.1515/9783110900019.205 ROHDENBURG, Günter. 2006. The Role of

Functional Constraints in the Evolution of the English Complementation System. Syntax, Style and Grammatical Norms: English from 1500-2000, eds. Christiane Dalton-Puffer, Dieter Kastovsky, Nikolaus Ritt and Herbert Schendl. 143-166. Bern: Peter Lang. https://doi. org/10.3726/978-3-0351-0272-7
ROHDENBURG, Günter. 2007. Functional Constraints in Syntactic Change: The Rise and Fall of Prepositional Construction in Early and Late Modern English. English Studies 88 (2): 217-233. https://doi. org/10.1080/00138380601042824 ROHDENBURG, Günter. 2014. On the Changing Status of that-clauses. Late Modern English Syntax, ed. Marianne Hundt. 155-181. Cambridge: Cambridge University Press. https:// doi.org/10.1017/ CBO9781139507226.013

ROMASANTA, Raquel P. 2017. Contactinduced variation in clausal verb complementation: the case of REGRET in World Englishes. Alicante Journal of English Studies 30: 121-147. https:// doi.org/10.14198/raei.2017.30.05

RUDANKO, Juhani. 1998. To Infinitive and to -ing Complements: A Look at Some Matrix Verbs in Late Modern English and Later. English Studies 79 (4): 336348. https://doi.

org/10.1080/00138389808599138

RUDANKO, Juhani. 2006. Watching English Grammar Change: A Case Study on Complement Selection in British and American English. English Language and Linguistics 10 (1): 3148. Cambridge: Cambridge University Press. https://doi.org/10.1017/ S1360674306001791

RUDANKO, Juhani. 2010. Explaining Grammatical Variation and Change: A Case Study of Complement Selection in American English over Three Decades. Journal of English Linguistics 38 (1): 4-24. https://doi. org/10.1177/0075424209335495

RUDANKO, Juhani. 2011. Changes in Complementation in British and American English: Corpus-based Studies on Non-Finite Complements in Recent English. New York: Palgrave 
Macmillan. https://doi. org/10.1057/9780230305199

RUDANKO, Juhani. 2012. Exploring Aspects of the Great Complement Shift, with Evidence from the TIME Corpus and COCA. The Oxford Handbook of the History of English, eds. Terttu Nevalainen and Elizabeth Closs Traugott. 222-232. New York: Oxford University Press. https://doi. org/10.1093/ oxfordhb/9780199922765.013.0021 RUDANKO, Juhani. 2015. 'Wheedled Me Into Lending Him My Best Hunter’: Comparing the Emergence of the Transitive into -ing Construction in British and American English. Perspectives on Complementation: Structure, Variation and Boundaries, eds. Mikko Höglund, Paul Rickman, Juhani Rudanko and Jukka Havu. 128140. London: Palgrave Macmillan. https://doi.org/10.1057/9781137450067 RUDANKO, Juhani. 2017. Infinitives and Gerunds in Recent English: Studies on Non-finite Complements with Data from Large Corpora. New York: Palgrave Macmillan. https://doi. org/10.1007/978-3-319-46313-1

SAARIMÄKI, Veera. 2018. Sentential Complementation of propose in Recent British English. Changing Structures: Studies in Constructions and Complementation, eds. Mark Kaunisto, Mikko
Höglund and Paul Rickman. 109-128. Amsterdam: John Benjamins. https:// doi.org/10.1075/slcs.195.07saa SEOANE, Elena. 2017. Syntax. In Early Modern English, Vol. 4 of The History of English, eds. Alexander Bergs and Laurel Brinton. 68-88. Berlin: De Gruyter Mouton. https://doi. org/10.1515/9783110525069-005 TRAUGOTT, Elizabeth. 1992. Syntax. In 1066-1476, Vol. 2 of The Cambridge History of the English Language, ed. Richard M. Hogg. 168-289. Cambridge: Cambridge University Press. https:// doi.org/10.1017/

CHOL9780521264747.005

VISSER, Federicus Theodorus. 1963-1973. An Historical Syntax of the English Language. 4 parts. Leiden: E.J. Brill. vosberg, Uwe. 2003. Cognitive Complexity and the Establishment of -ing Constructions with Retrospective Verbs in Modern English. Insights into Late Modern English, eds. Marina Dossena and Charles Jones. 197-220. Bern: Peter Lang. VOSBERG, Uwe. 2009. Non-finite Complements. One Language, Two Grammars? Differences Between British and American English, eds. Günter Rohdenburg and Julia Schlüter. 212-227. Cambridge: Cambridge University Press. https://doi. org/10.1017/CBO9780511551970.012 